DOC.

D101.60/2:

1738

DOC ,

D101,60/2:

1738

\author{
U.S. Army Research Institute \\ for the Behavioral and Social Sciences
}

Research Report 1738

\title{
The Division Level Military Decision-Making Process (MDMP): \\ Design and Development of a Prototype Computer-Based Training Product
}

\author{
James H. Centric \\ TRW Systems and Information Technology Group \\ Margaret S. Salter \\ U.S. Army Research Institute
}

The Library of the

MAY 171999

University of Illinois

March 1999 